\title{
Finite Element Analysis of Friction Plate of Diaphragm Spring Clutch for TD-3250 Vehicle
}

\author{
Suyog Vitnor ${ }^{1}$, Mukund Kavade ${ }^{2}$ \\ ${ }^{1}$ M.Tech CAD/CAM/CAE, Mechanical Engineering Department, Rajarambapu Institute of Technology, Islampur, India
}

${ }^{2}$ M.E. Production Associate Professor, Mechanical Engineering Department, Rajarambapu Institute of Technology, Islampur, India

\begin{abstract}
This paper presents finite element analysis of grooved friction plate of Diaphragm spring Clutch which has been used to study of temperature distribution \& thermal stresses during single engagement. The commercial software CATIA V.5 \& ANSYS 15 is used for modelling of clutch parts \& Thermo-mechanical analysis of friction plate respectively. When clutch begins to engage, the high thermal stresses \& high temperature distribution generated between the contacting surfaces such as pressure plate, clutch disc and flywheel due to the frictional heating which is generated in $1.85 \mathrm{sec}$ slip-time. The thermo-mechanical problems such as thermal deformations and thermo-elastic instability due to hot spot leads to thermal cracking, this is the main reason of clutch failure which is occurred in previous design of TD 3250 vehicle clutch system, hence there is need to do thermo-mechanical analysis of clutch component. The main objective of this paper is to obtain a minimum safe stress value \& temperature distribution of friction plate by using analytical \& numerical calculation.
\end{abstract}

Keywords: Thermo-elastic instability, thermo-mechanical analysis, Diaphragm spring Clutch, Finite Element Analysis

\section{Introduction}

A clutch system is one of the important components of a vehicle that plays role in the transmission of power and control of motion from engine to transmission system. The main primary function of the clutch is to transmit the torque from engine to driven shaft \& engage and disengage the transmission system. The secondary function is related to vibration \& damping. When the friction clutch begins to engage, slipping occurs between the contact surfaces such as pressure plate, friction plate and flywheel and due to this slipping, heat energy will be generated on friction plate surfaces. At high relative sliding velocity, high quantity of frictional heat is generated which lead to high temperature rise on the friction plate surfaces and hence thermo-mechanical problems such as thermal deformations and thermo-elastic instability can occur. The high thermal stresses, temperature distribution \& thermal cracking generated between the contacting surfaces of clutch system such as pressure plate, clutch disc and flywheel due to the frictional heating during the slipping period, are considered to be one of the main reasons of clutch failure for contact surfaces. In some cases temperature exceeds the maximum temperature limit of the material and eventually leads to premature failure. This is the main problem which occurs in TD 3250 Force motor-Travel vehicle.

Hence there is need to do transient thermal analysis for obtaining temperature distribution \& transient thermal analysis for obtaining thermal stress of clutch disc of diaphragm spring clutch. Optimization of friction plate for temperature distribution is done by changing the design parameter \& comparing its result in ANSYS software

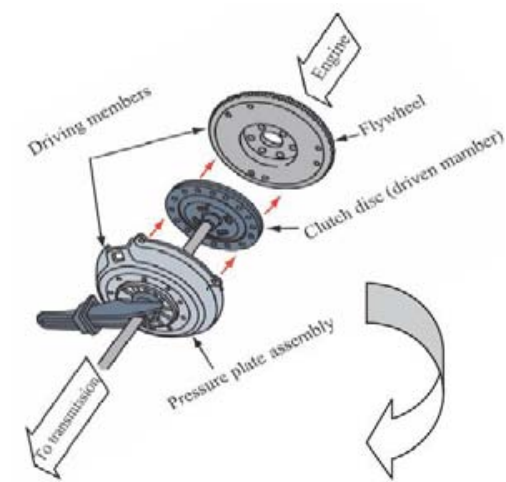

Figure 1.1 Clutch Assembly

\section{Literature}

Purohit \& Khitoliya [1] has worked on design \& structural analysis of clutch parts by using solid work \& ANSYS software. The plots for equivalent stress, total deformation and factor of safety were obtained and the design was continuously optimized till a safe design was obtained.

Tien-Chen Jen [2] has done the thermal analysis of wet Friction plate which is subjected to constant energy engagement. The theoretical and experimental thermal analysis is conducted on the plates. A numerical model is developed for computation of the temperature distribution in the steel plate. In experimental analysis, thermocouples are used for detecting the temperature rise during one clutch engagement. Finally, the temperature rises predicted by the analytical and numerical models are compared to the experimental data .

Sfarni \&Bellenger [3] has worked on numerical \& experimental study of automotive friction disc with contact pressure analysis for prediction of wear rate. In this work, they propose to verify that the determination of the contact pressure distribution on the facings at the beginning of the 


\section{International Journal of Science and Research (IJSR) \\ ISSN (Online): 2319-7064}

Index Copernicus Value (2013): 6.14 $\mid$ Impact Factor (2015): 6.391

engagement which helps for estimating the embedding phenomenon.

Doman \&Fujii [4] has worked on to show how shot-peening affects the nonlinear response of diaphragm springs. They have done the mechanism for shot peening that means, residual stress due to shot-peening on the $\mathrm{P}-\mathrm{d}$ curve by using the finite element method by considering geometrical and material nonlinearities. For diaphragm springs with shotpeening, the $\mathrm{P}-\mathrm{d}$ characteristic curve can be precisely predicted by nonlinear FEM considering both material and geometry nonlinearities.

Li Wenbin [6] worked on simulation of engagement carbon fabric wet clutch by analytical \& experimental method. The modified numerical model was developed for a carbon fabric wet clutch by taking the influences of the applied pressure, the permeability and the fluid viscosity on the engagement characteristics. The results indicate that the torque increases, then engagement time decreases and the friction-induced shudder increases with the increase of applied pressure.

The object of the present work is to observe the stress distribution \& temperature distribution of the friction plate which is always fails during the operation .The Finite Element Analysis providing a means for non-destructive analysis, which is used to analyse the clutch component. This paper deals with design, modelling, and analysis of Diaphragm Spring Clutch for TD 3250 Force-motor vehicle.

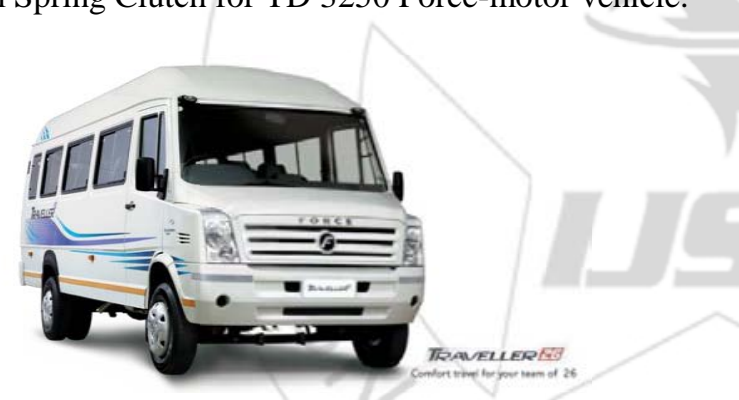

Figure 2.1: TD 3250 vehicle

\section{Methodology}

\subsection{Design of Diaphragm Spring Clutch}

Let us consider, $r_{1} \& r_{2}=$ internal and external radii of contact surface respectively,

$\mathrm{W}=$ axial load exerted by actuating springs $\mathrm{N}$,

$\mu=$ coefficient of friction for the contact surfaces,

$\mathrm{p}=$ normal pressure $(\mathrm{Pa})$.

Though the value of varies from point to point on the contact surface as it depends upon the relative velocity and the intensity of pressure, it is assumed to be constant for simplicity in calculations.

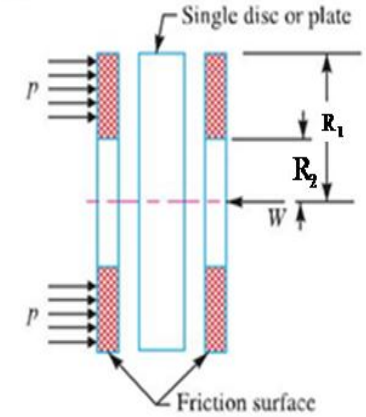

(a)

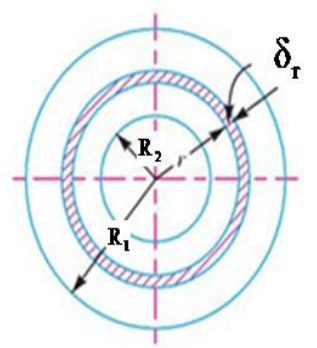

(b)
Figure 3.1 Simplified representation of a Single Plate Clutch

Then total axial load, $W=\int_{\mathrm{r} 1}^{\mathrm{r} 2} 2 \pi r \mathrm{r} r \mathrm{rp}$ and Total frictional torque, $\mathrm{T}=\int_{\mathrm{r} 1}^{\mathrm{r} 2} 2 \mu \pi \mathrm{r}^{2} \mathrm{drp}$

The above two equations can be integrated using either of two assumptions that,

1) The intensity of pressure is uniform, or

2)The rate of wear is uniform.

3) When the two surfaces have perfect contact, the pressure p is uniform over the entire surface. The intensity of pressure becomes,

$$
P=\frac{W}{\pi\left(r^{2}-r 1^{2}\right)}
$$

Therefore the total frictional torque, $\mathrm{T}=\int_{\mathrm{r} 1}^{\mathrm{r} 2} 2 \mu \pi \mathrm{pr}^{2} \mathrm{dr} T$ $=2 \mu \pi \frac{W}{\pi\left(r 2^{2}-r_{1}^{2}\right)} \frac{\left(\mathrm{r}^{2}-\mathrm{r1}^{3}\right)}{a} \mathrm{~T}=\frac{2}{3} \mu \frac{W\left(\mathrm{r}^{3}-\mathrm{r} 1^{3}\right)}{\left(\mathrm{r}^{2}-\mathrm{r}^{2}\right)}, \mathrm{Nm}$

This assumption is normally used in situations involving power absorption by friction. This provides higher frictional torque than the case based on uniform wear. [9]

\subsection{Design consideration of Diaphragm spring:-}

Design Considerations: - So the next step involves the considerations for designing a clutch and specifies its application. Following are the design considerations for a single plate dry clutch:-

1) The suitable material for the friction surface should be selected \& The moving parts of the clutch should have low weight in order to minimize the inertia

2) The clutch should have provision for facilitating repairs

3 ) It is usually designed to transmit $150-175 \%$ of the maximum engine torque.

4) Size of clutch should be small

5) Proper ventilation should be provided for dissipation of heat

6) Clutch should be positively take the drive with occurrence of sudden jerks.

The material which is used for pressure plate, flywheel, damper spring \& friction plate are Cast iron, 2D grade spring steel, \& Valeo F510 respectively. 


\section{International Journal of Science and Research (IJSR) \\ ISSN (Online): 2319-7064 \\ Index Copernicus Value (2013): 6.14 | Impact Factor (2015): 6.391}

\subsection{Modelling \& Transient Thermal Analysis:-}

Firstly, modelling of clutch assembly is done by using CATIA V5 software. The dimension of friction plate, cushion plate, flywheel \& pressure plate are given in table no. 3.1. The diameter of flywheel \& pressure plate is always greater than dimension of friction plate. After assembly, geometric editing \& meshing is done in ANAYS software .In geometric editing ,surfaces of friction plate are divided in 6 division for giving the loading condition in ANSYS software. After meshing, quality of meshing is given below,

Table 3.1: Quality criteria in ANSYS

\begin{tabular}{|c|c|}
\hline Description & Achieved Quality Criteria \\
\hline Skewness & 0.97 \\
\hline Aspect Ratio & 7.7 \\
\hline Elements & 291613 \\
\hline Nodes & 503322 \\
\hline
\end{tabular}

The material properties are already given in table no 2 which is imported in ANSYS software. Due to frictional heating maximum heat is generated between the contacting surfaces. Hence there is need of calculation heat flux on area of friction surface. for thermal boundary conditions. Natural convection i.e. $5 \mathrm{~W} / \mathrm{m}$ is considered for heat dissipation. The convection will be occurred from outer \& inner surfaces of contacting surfaces. In this paper, there is comparison of temperature distribution for three types of design i.e. without groove without hole clutch assembly, with groove without hole clutch assembly \& with groove \& hole assembly.

\subsection{Calculation of Heat generation for transient thermal analysis}

The large amount of the kinetic energy is converted into thermal energy during slipping period (ts). In this, the friction energy consumption due to slipping is transformed into heat energy, which is distributed in the friction interface. Then, the total heat generated during the slipping is given as follows,

$Q_{(r, t)}=\mu P V_{s} ; 0<t<t_{s} \quad$ Where, $V_{s}=w_{s} \mathrm{r}$

$V_{s}$ means sliding velocity and $w_{s}$ means sliding angular velocity $(\mathrm{rad} / \mathrm{sec})$. Assume the sliding angular velocity decreases linearly with time as, $w_{s}(t)=w_{0}\left(1-\frac{t}{t_{s}}\right) ; 0<t<t_{s}$

Where $w_{0}$ is the initial sliding angular velocity when the clutch starts to slip $(\mathrm{t}=0)$.

The heat flux on the clutch surfaces at any time of slipping is, $Q_{(r, t)}=f_{c} \mu P r w_{0}\left(1-\frac{t}{t_{s}}\right) ; 0<t<t_{s}$

$f_{c}$ is the heat partition ratio which avoids division of heat entering in clutch, pressure plate, flywheel is given by,

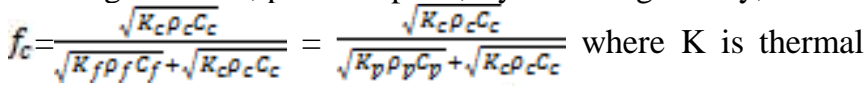
conductivity, $\mathrm{C}$ is specific heat, $\rho$ is density for pressure plate, flywheel \& friction plate.[10]
Heat flux are calculated for different areas at different time is given in following table which is input parameter for Transient Thermal Analysis ,

Table 3.2: Input parameter Transient Thermal analysis

\begin{tabular}{|c|c|c|c|c|c|}
\hline \multirow{2}{*}{$\begin{array}{c}\text { Heat flux at } \\
\text { Radius } \\
\left(\mathrm{W} / \mathrm{m}^{2}\right)\end{array}$} & \multicolumn{5}{|c|}{ Slipping Time (sec) } \\
\hline & 0.37 & 0.74 & 1.11 & 1.48 & 1.84 \\
\hline 80 to 90 & 38.93 & 29.19 & 19.46 & 9.73 & 0.26 \\
\hline 90 to 100 & 43.51 & 32.63 & 21.75 & 10.87 & 0.29 \\
\hline 100 to 110 & 48.09 & 36.06 & 24.04 & 12.02 & 0.32 \\
\hline 110 to 120 & 52.67 & 39.50 & 26.33 & 13.16 & 0.35 \\
\hline 120 to 130 & 57.25 & 42.93 & 28.62 & 14.31 & 0.38 \\
\hline 130 to 140 & 61.83 & 46.37 & 29.91 & 15.45 & 0.41 \\
\hline
\end{tabular}

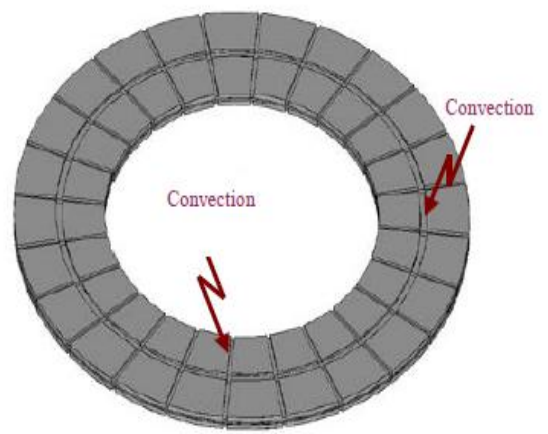

Figure 3.1: Boundary condition for thermal analysis

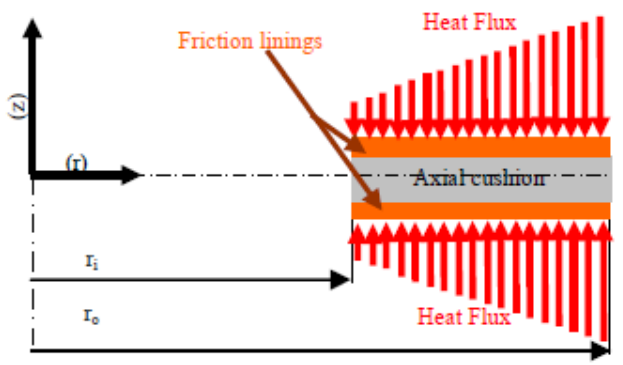

Figure 3.2: Thermal boundary condition for uniform pressure theory

Table 3.3: Properties of material

\begin{tabular}{|l|l|}
\hline Outer diameter of friction plate $(\mathrm{m})$ & 0.28 \\
\hline Inner diameter of friction plate $(\mathrm{m})$ & 0.16 \\
\hline Thickness of friction material, t (m) & 0.0038 \\
\hline Thickness of the axial cushion, t (m) & 0.002 \\
\hline Depth of the grooves, [m] & 0.0008 \\
\hline Maximum pressure , p (N/m ) & 128350 \\
\hline Maximum angular slipping speed, $\omega(\mathrm{rad} / \mathrm{sec})$ & 209.43 \\
\hline Conductivity of friction material, K (W/mK) & 0.75 \\
\hline $\begin{array}{l}\text { Conductivity of pressure plate \& flywheel, } \mathrm{K}_{\mathrm{p}} \\
\text { \& K }(\mathrm{W} / \mathrm{mK})\end{array}$ & 52 \\
\hline Density of friction material, $\rho(\mathrm{kg} / \mathrm{m})$ & 733 \\
\hline $\begin{array}{l}\text { Densiţy of pressure plate \& flywheel, } \rho_{\mathrm{p}} \& \rho_{\mathrm{f}} \\
\text { (kg/m ) }\end{array}$ & 7800 \\
\hline Specific heat of friction material, c (J/KgK) & 1500 \\
\hline $\begin{array}{l}\text { Specific heat of pressure plate \& flywheel, } \\
\text { c \& c (J/KgK) }\end{array}$ & 500 \\
\hline Thickness of Flywheel (m) & 0.015 \\
\hline Thickness of Pressure plate (m) & 0.0127 \\
\hline
\end{tabular}




\section{International Journal of Science and Research (IJSR) \\ ISSN (Online): 2319-7064}

Index Copernicus Value (2013): 6.14 | Impact Factor (2015): 6.391

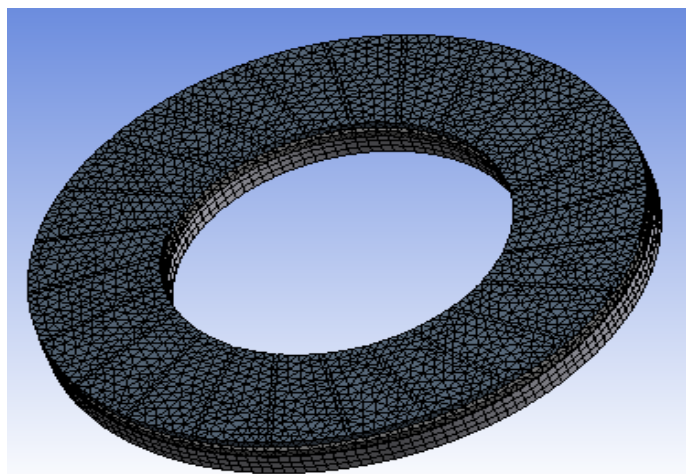

Figure 3.3: Meshing of clutch assembly

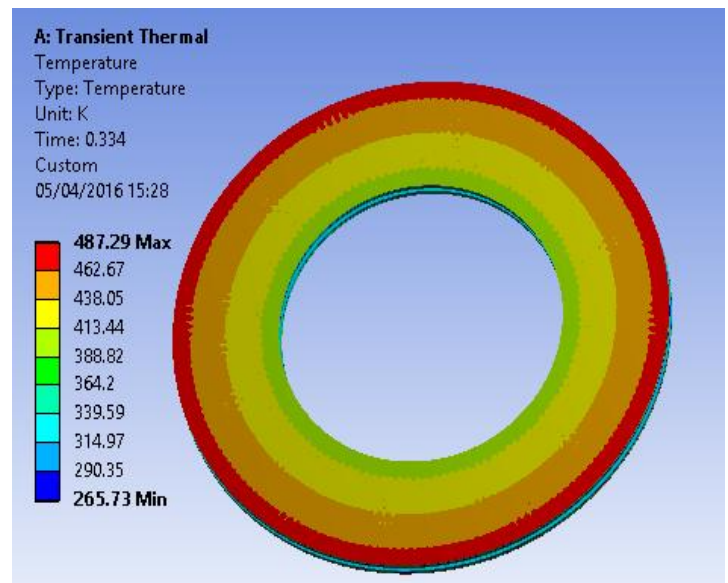

Figure 3.4: Temperature Disritubution for (a) type design

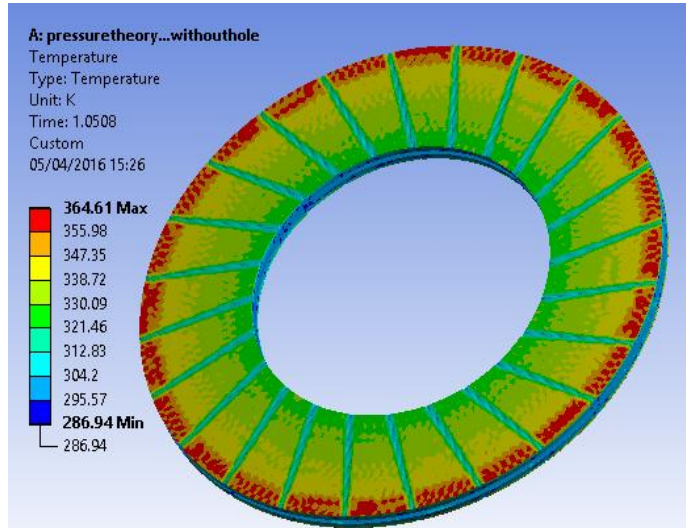

Figure 3.5: Temperature Disritubution for (b) type design

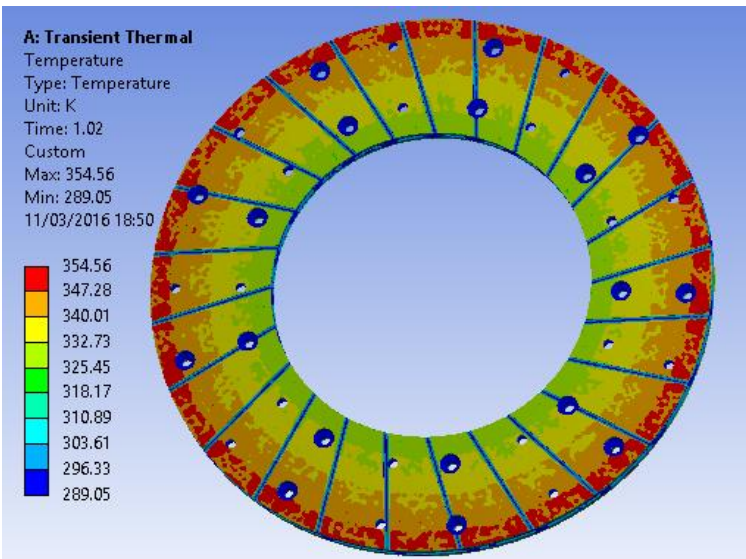

Figure 3.6: Temperature distribution on surface of friction plate for (c) type design

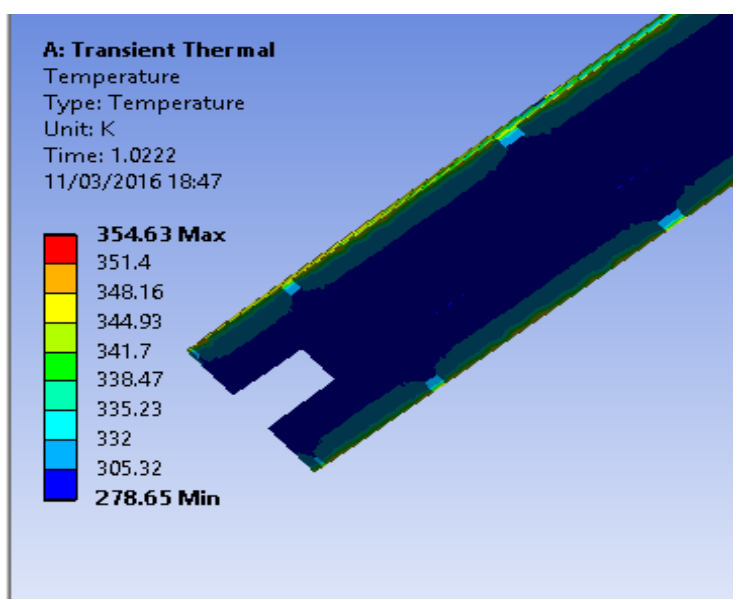

Figure 3.7: Temperature distribution across thickness of assembly at $1.84 \mathrm{sec}$

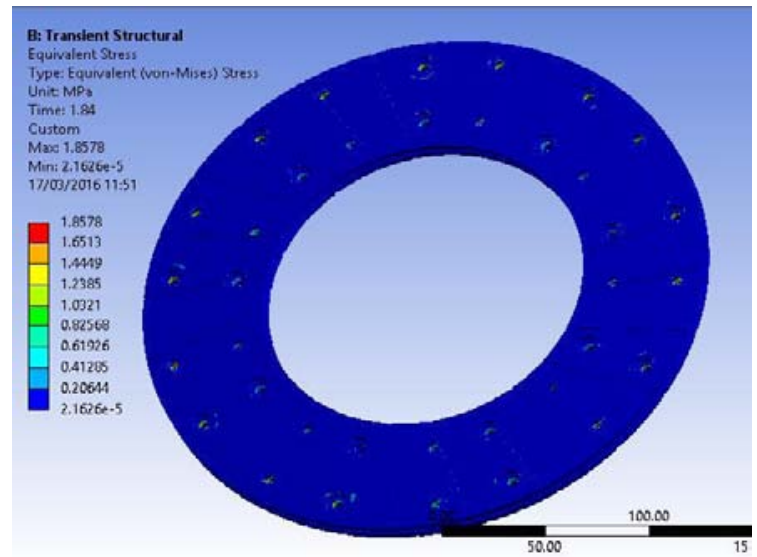

Figure 3.8: Thermal stress distribution on Friction Plate

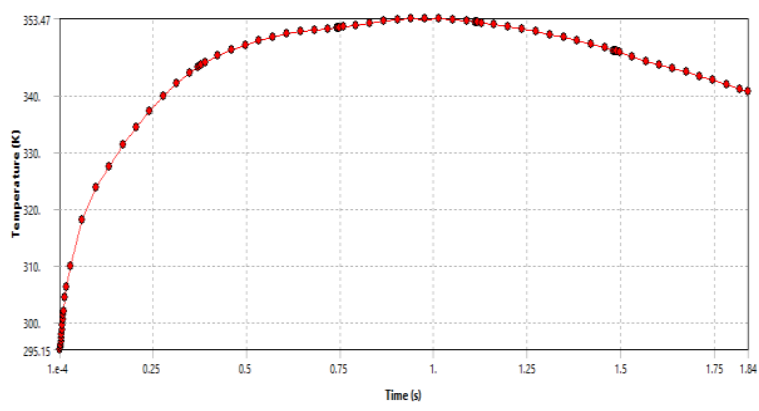

Figure 3.9: Temperature vs time in ANSYS software

\section{Result \& Conclusion}

In this paper, there is comparison of three types of design i.e. i.e. without groove without hole clutch assembly, with groove without hole clutch assembly \& with groove \& hole assembly for TD 3250 heavy duty vehicle. From these, the result for with groove \& with hole assembly is good as compared to others because temperature distribution is lower in this case .The maximum temperature in without hole-without groove assembly (a), without hole-with groove (b) \& with hole-with groove assembly (c) are 465K , 365 K \& 354 K respectively. The graph for temperature distribution is given in fig no 3.9. From this graph temperature increases from up to $1.02 \mathrm{sec}$ after that decreases slowly because of convection phenomenon. The temperature is increases from inner radius to outer radius hence there is always maximum temperature 


\section{International Journal of Science and Research (IJSR) \\ ISSN (Online): 2319-7064 \\ Index Copernicus Value (2013): 6.14 | Impact Factor (2015): 6.391}

at outer radius. Heat Generation in Slip time $(1.85 \mathrm{sec})$ at full load condition is acceptable i.e. $123.92 \mathrm{KJ}<140$. The temperature distribution is obtained by transient thermal analysis in ANSYS software which is in safe condition. After that transient structural analysis is done for thermal stress due to temperature distribution. In with hole-with groove assembly shows minimum stress values because temperature distribution is lower as compared to others. Hence whole clutch assembly is safe.

Table 4.1: Result table

\begin{tabular}{|c|c|c|c|}
\hline Description & $\begin{array}{c}\text { Without-hole } \\
\text { without groove } \\
\text { (a) }\end{array}$ & $\begin{array}{c}\text { Without hole } \\
\text { with groove } \\
\text { (b) }\end{array}$ & $\begin{array}{c}\text { With hole \& } \\
\text { groove (c) }\end{array}$ \\
\hline Temperature & $465 \mathrm{~K}$ & $365 \mathrm{~K}$ & $354 \mathrm{~K}$ \\
\hline Remark & Worst design & Good design & Better design \\
\hline
\end{tabular}

\section{Acknowledgement}

I also thank my guide Prof. M. V. Kavade from mechanical engineering department of Rajarambapu Institute of technology, Islampur for consistent helping a lot for doing this research work and for comments that greatly improved the manuscript. Also I thank our colleagues, who provided insight, and expertise that greatly assisted the research and my family who always support me.

\section{References}

[1] Rajesh Purohit, Pooja Khitoliya and Dinesh Kumar Koli, "Design and Finite Element Analysis of an Automotive Clutch Assembly" Elsevier,Procedia Materials Science 6 ( 2014 ) 490-502 .

[2] Tien-Chen Jen, Daniel James Nemecek "Thermal Analysis of wet-disc clutch subjected to constant energy engagement" Elsevier, International Journal of Heat and Mass Transfer 51 (2008) 1757-1769

[3] Samir Sfarni, Emmanuel Bellenger, Fortin, Matthieu Malley, "Numerical and experimental study of automotive riveted clutch discs with contact pressure analysis for the prediction of facing wear" Elsevier, Finite Elements in Analysis and Design 47 (2011) 129141

[4] Yasunori Domana, Toru Fujii, Kazuya Okubob, Hanjun He, "Influence of residual stress on load-deflection curve of diaphragm spring of automobile clutch" ScienceDirect, JSAE Review 24 (2003) 197-203

[5] ShoaibIqbal, FaridAl-Bender, Ompusunggu,Bert Pluymers, Wim Desmet,“ Modeling and analysis of wet friction clutch engagement dynamics" Science-Direct, Mechanical Systems and Signal Processing.

[6] Li Wenbin,Huang Jianfeng,Fei Jie , Cao Liyu,Yao Chunyan,Wang Wenjing," Simulation of the engagement of carbon fabric wet clutch: Analytical and experimental comparison", Science-Direct, Tribology International 90(2015)502-508

[7] Norton, Spring Design,in "Machine design book-An integrated Approach" 854-874 .

[8] Harold A. Roth Barth, Friction Clutches, in "Mechanical handbook design",22.1-23.32

[9] V.B Bhandari, "Machine Design"
[10] Wassan abdulha "Finite Element Analysis for grooved Friction clutches" SAE paper 2015-010688,doi:4271/2015

[11] Jaya Hind Industies. Ltd Technical Library, Design Of Clutch Handbook.

\section{Author Profile}

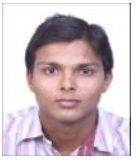

Mr. Suyog Kailas Vitnor has received B.E. in Mechanical Engineering degree in 2014 from K.K.Wagh college of Engineering, Nashik (Pune University) and pursuing Master of Technology (MTech) CAD/CAM/CAE Engineering for year 2016 from Rajarambapu Institute of Technology, Islampur, Sangli.

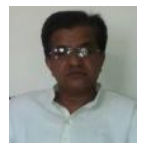

Prof. M.V.Kavade has received B.E. in Mechanical Engineering in 1986 \& Master of Engineering in production engineering in year 2000 from Government College of Engineering, Karad. Now, he is Associate professor at Rajarambapu Institute of Technology, Islampur, and Sangli. He is having 8 years of industrial experience and 21 years of teaching experience. 